\title{
SIGNIFICANCE OF THE DMF(T+t) INDEX FOR THE CHILDREN WITH PREMATURELY EXTRACTED TEETH
}

\author{
Hristina Arnautska ${ }^{1}$, Radosveta Andreeva ${ }^{2}$, Ani Belcheva ${ }^{3}$, Vera Krumova ${ }^{4}$ \\ ${ }^{1}$ Department of Prosthetic Dentistry and Orthodontics, Faculty of Dental Medicine, \\ Medical University of Varna \\ ${ }^{2}$ Department of Pediatric Dentistry, Faculty of Dental Medicine, \\ Medical University of Varna \\ ${ }^{3}$ Department of Pediatric Dentistry, Faculty of Dental Medicine, \\ Medical University of Plovdiv \\ ${ }^{4}$ Department of Orthodontics, Faculty of Dental Medicine, Medical University of Sofia
}

\begin{abstract}
Premature extraction of temporary teeth is a consequence of different factors such as socio-economic status of the population, level of caries activity, oral hygiene, presence of fluoride in water, philosophy of the dentist. The aim of this article is to compare the DMF $(\mathrm{T}+\mathrm{t})$ between children with premature extraction and those without premature extraction. Subject of monitoring of the clinical research were 140 children between 6 and 9 years old. The clinical group consisted of 90 children with prematurely extracted teeth, divided into three groups. The control group consisted of 50 children with intact denture. The dental status was examined and registered according to the $\mathrm{WHO}$ by the DMF $(\mathrm{T}+\mathrm{t})$. There was a statistically significant difference in the distribution of caries $\mathrm{DMF}(\mathrm{T}+\mathrm{t})$ between the control groups $(2.34 \pm 019)$ and clinical groups (between $5.17 \pm 0.33$ and $6.40 \pm 0.41$ ). The children with premature extraction of temporary teeth had higher caries activity compared to the control group (children without early loss of teeth). The children with prematurely extracted temporary teeth and severe orthodontic deformation had the highest prevalence of $\operatorname{DMF}(\mathrm{T}+\mathrm{t})$. These results demonstrate the connection between $\operatorname{DMF}(\mathrm{T}+\mathrm{t})$, malocclusions and the need for prophylaxis.
\end{abstract}

Keywords: DMF index, prematurely extraction, decidious teeth, orthodontic deformations

Address for correspondence:

Radosveta Andreeva

Faculty of Dental Medicine,

Medical University of Varna

55 Marin Drinov Str.

9002 Varna, Bulgaria

e-mail:doctor_ra@abv.bg

Received: November 8, 2015

Accepted: December 1, 2015

\section{INTRODUCTION}

Premature extraction of temporary teeth is a consequence of different factors like socio-economic status of the population, the level of caries activity, oral hygiene, presence of fluoride in water, philosophy of the dentist $(1,2)$.

Premature extraction of temporary teeth is a common finding among children and is present in $20-65 \%$ of the scientific publications (3-5). Tooth decay and it's complications are the main factor for premature extraction of temporary teeth. It is the most common hard dental tissue chronic disease (6). Worldwide, $60-90 \%$ of the children in scholar age have carious lesions according to WHO (2012). A lot 
of temporary teeth can be saved from premature extraction if treated well-timed and adequately.

\section{THE AIM}

The aim of this article is to compare the DMF $(\mathrm{T}+\mathrm{t})$ between children with premature extraction and those without premature extraction.

\section{METHODS AND MATERIALS}

Subject of monitoring of the clinical research were 140 children between 6 and 9 years old. The clinical group consisted of 90 children with prematurely extracted teeth. The patients from the clinical group were divided into three groups of 30 patients:

* Patients that have lost one or more tooth, that came to the clinic during the first 2 month after the extraction and had no orthodontic problems.

* Patients with prematurely temporary teeth extracted $>6$ months ago with mild orthodontic problems.

* Patients with prematurely temporary tooth lost $>6$ months ago and had severe orthodontic problems (II and III class Angle).

The control group consisted of 50 children with intact denture.

The dental status was examined and registered according to the WHO by the DMF $(\mathrm{T}+\mathrm{t})$. This index is one of the most often used in oral epidemiology to estimate the distribution of dental caries and need of treatment among the population. The index is based on clinical observation of patients with dental mirror, dental probe, cotton pellets and suction. DMF $(\mathrm{T}+\mathrm{t})$ represents the sum of the teeth with decay, missing teeth, and those with fillings. D- is for decay, $\mathrm{M}$ - is for missing, $\mathrm{F}$ - is filling and $\mathrm{T}+\mathrm{t}$ is used for teeth of the mixed dentition. The capital latter $\mathrm{T}$ marks the permanent dentition and the small $\mathrm{t}$ marks the temporary dentition (7).

\section{RESULTS AND DISCUSSION}

Table 1. Comparison of the DMF $(T+t)$ index, between the control and clinical group

\begin{tabular}{l|cc|cc|c}
\hline groups & $\begin{array}{c}\text { control }(\mathrm{n}=50) \\
\text { mean } \pm \text { SEM }\end{array}$ & $\begin{array}{c}\text { Group 1 }(\mathrm{n}=30) \\
\text { mean } \pm \text { SEM }\end{array}$ & $\begin{array}{c}\text { Group 2 }(\mathrm{n}=30) \\
\text { mean } \pm \text { SEM }\end{array}$ & $\begin{array}{c}\text { Group 3 }(\mathrm{n}=30) \\
\text { mean } \pm \text { SEM }\end{array}$ & P \\
\hline $\operatorname{DMF}(\mathrm{T}+\mathrm{t})$ & $2.34 \pm 019$ & $5.17 \pm 0.33$ & $5.60 \pm 0.40$ & $6.40 \pm 0.41$ & $<0.0001$ \\
\hline
\end{tabular}

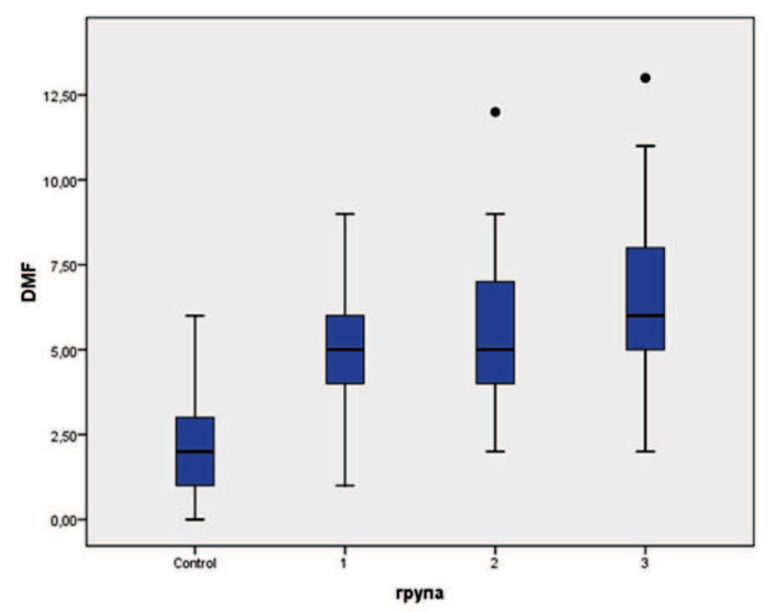

Figure 1. Box-plot diagram for the DMF $(T+t)$ index in the control and clinical groups

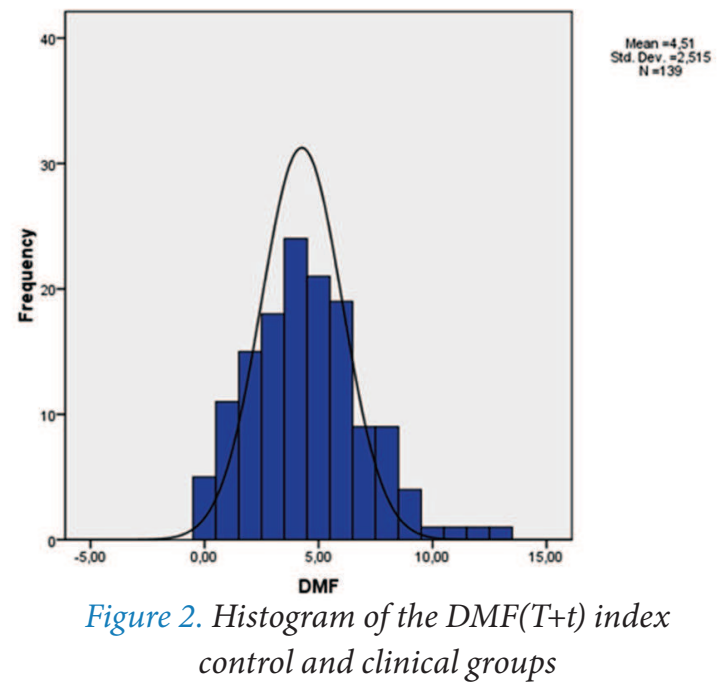

From table one we can see that there is a statistically significant difference in the distribution of caries $\mathrm{DMF}(\mathrm{T}+\mathrm{t})$ between the control groups and the clinical groups as well as between the clinical groups.

The children of the control group (without prematurely extracted teeth) have the smallest $(\mathrm{DMF}(\mathrm{T}+\mathrm{t}))--2.34$. The results are shown in a graphic by Box-plot diagram on Fig. 1. 
Hristina Arnautska, Radosveta Andreeva, Ani Belcheva et al.

The statistically significant difference between the control and the clinical groups is seen on the Box-plot diagram. There are some cases from the second and the third group with an extremely high $\mathrm{DMF}(\mathrm{T}+\mathrm{t})$ index around 12 . This result confirms the relationship between high caries activity and orthodontic deformation that is in both directions. Children with orthodontic deformation have higher plaque retention and a higher caries risk as a result. The caries complication also leads to premature tooth extraction that is one of the risk factors for orthodontic deformation development. Our results are confirmed by Ribagin and other authors $(4,7,8)$.

The results of the statistical analysis show the normal distribution of the $\mathrm{DMF}(\mathrm{T}+\mathrm{t})$ index (Fig. 2). Most of the examined children had a high caries risk and the DMF $(\mathrm{T}+\mathrm{t})$ was between 5 and 7 . Only a few cases had extremely high and extremely low values of DMF $(\mathrm{T}+\mathrm{t})$ index such as 0 or higher than 10 .

\section{CONCLUSION}

The data from the oral examination status showed that children with premature extraction of temporary teeth had higher caries activity compared to the control group (children without early loss of teeth). The children from the third group, with prematurely extracted temporary teeth and severe orthodontic deformation had the highest prevalence of $\operatorname{DMF}(\mathrm{T}+\mathrm{t})$. These results demonstrate the connection between $\mathrm{DMF}(\mathrm{T}+\mathrm{t})$, malocclusions and the need for prophylaxis.

\section{REFERENCE}

1. Drury T, Horowitz A. Diagnosing and reporting early child caries for research purpose. J Publ Health Dent. 1999;59:192-197.

2. Kelner N, Rodrigues MJ, Miranda K. Prevalence of early loss of deciduous molars in children attending the FOP/UPE in 2002 and 2003. Dent Clin Sci Recife. 2005;4:213-8.

3. Greenberg R. Medical epidemiology. Prentice-Hall International, Inc.; 1995. 146p.

4. Melsen B, Terp S. The influence of extractions caries cause on the development of malocclusion and need for orthodontic treatment. Swed Dent J Supplement. 1982;15:163-9.

5. Northway WM, Wainright RW. D E space - a realistic measure of changes in arch morphology: space loss due to unattended caries. J Dent Res. 1980 Oct;59(10):1577-80.

6. Peneva M. Response rates of tooth decay. In: Caries in the $21^{\text {st }}$ century. East-West; 2008. 29-33. Bulgarian.

7. Edward Lo. Caries prevention. Strategies. Epidemiology. Chicago: Quintessence; 2005;10(4):19-23.

8. Ribagin L. Changes in oral status in children with tooth-jaw deformities. [dissertation]. [Sofia]; 2015. 5-47. Bulgarian. 